\title{
PATTERN AND RISK FACTORS OF SPORT INJURIES AMONG AMATEUR FOOTBALL PLAYERS IN KANO, NIGERIA
}

original paper

( ) University School of Physical Education in Wroclaw

DOI: https://doi.org/10.5114/hm.2020.93425

\author{
BASHIR BELLO ${ }^{1}$, USMAN BALARABE SA`AD ${ }^{1}$, AMINU A. IBRAHIM ${ }^{1}$, \\ ABDULRAHMAN A. MAMUDA ${ }^{2}$ \\ ${ }^{1}$ Department of Physiotherapy, Faculty of Allied Health Sciences, College of Health Sciences, Bayero University, \\ Kano, Nigeria \\ ${ }^{2}$ Orthopedic Unit, Department of Surgery, Bayero University, Kano, Nigeria
}

\section{ABSTRACT}

Purpose. The purpose of the study was to evaluate football injuries and associated factors in male amateur football players in Kano, North West Nigeria.

Methods. A descriptive, cross-sectional survey was conducted among 118 registered male amateur football players aged 16-30 years. The participants were recruited from 7 local football clubs in Kano city. A modified post-season injury questionnaire was used to collect data on football injuries and associated factors. Descriptive and inferential statistics were applied to analyse the data with the IBM SPSS version 20.0 software.

Results. The response rate was 100\%. Most injuries (78.3\%) occurred in the lower extremity, with knee injury being the most common (28.3\%), followed by ankle injury (21.7\%). Upper extremity injury accounted for 13.3\%, with shoulder and elbow being the most affected parts (8.3\% each). Rough tackle from an opponent (67.2\%) was the major cause of football injury. No significant association was found between age, dominant leg, player's position, and football injuries across various parts of the body $(p>0.05)$. However, there was a significant relationship between previous injury and thigh and knee injuries. Furthermore, the majority of the players (42.6\%) applied self-treatment, with sole physiotherapy (11.5\%) being the least frequently received treatment.

Conclusions. The factor most commonly associated with football injuries among male amateur football players in Kano was rough tackle from an opponent, with knee being the most affected body part.

Key words: football injury, amateur football players, associated factors

\section{Introduction}

Football is currently the most popular competitive sport in the world. According to a survey by the Federation of International Football Associations (FIFA), in 2006, there were about 265 million footballers in the world, including males and females; with referees and football officials, they made a total of 270 million individuals [1]. This makes up about $4 \%$ of the world's population that are currently playing a football game. Africa comprised 17\% (46 million) of the world footballers, and Nigeria has the highest number of male and female footballers (over 6.5 million players) in all categories of participation [1].
The benefits derived from football can be viewed in different perspectives. For example, football sport is an effective way to increase the level of physical activity and fitness [2]. The importance of this sport in a developing country cannot be overstated since it has the potential to contribute to both personal and social development. Football is a source of income to the players, both amateurs and professionals. It also generates tax revenue to the government through competition hosting, tickets fees, and won trophies [2-4].

Football is a game of strength, speed, power, and endurance exhibited during the play. However, because it involves dynamic movements, injuries are inevitable during matches or training [5]. Football injuries make

Correspondence address: Bashir Bello, Department of Physiotherapy, Faculty of Allied Health Sciences,

College of Health Sciences, Bayero University Kano, No. 234 Gwarzo road, newsite, P.M.B. 3011, Kano, Kano State,

Nigeria, e-mail: bbello.pth@buk.edu.ng

Received: February 24, 2019

Accepted for publication: August 7, 2019

Citation: Bello B, Sa'ad UB, Ibrahim AA, Mamuda AA. Pattern and risk factors of sport injuries among amateur football players in Kano, Nigeria. Hum Mov. 2020;21(4):61-68; doi: https:/doi.org/10.5114/hm.2020.93425. 
B. Bello, U.B. Sa’ad, A.A. Ibrahim, A.A. Mamuda, Pattern of sport injuries among amateur football players

players more vulnerable to future injury (re-injury) and result in financial consequence as all kinds of match bonuses, training allowances, etc. could not be gained by the affected player owing to the loss of playing time. Additionally, football injuries affect not only the career of the player himself but also the team's overall performance and success [2]. Injuries are an expected consequence of football matches or training and are not generally a result of a single causative factor but remain associated with various risk factors interacting at a given time and more commonly involving lower than upper extremities [3].

In Nigeria, football is unarguably the most popular sport, with an increasing number of tournaments organized both locally and internationally. Moreover, numerous amateur football clubs are evolving and producing elite football players across the nation. However, the increase in popularity of this sport and the physical and mental demands from a footballer in addition to limited sport medicine resources [6] could lead to a higher incidence of football injuries. Though several studies have been conducted on soccer injuries and related factors among football players, a vast majority of them [4-7] were performed in the Western world among professional football players, particularly during international tournaments [2, 8, 9]. While some studies have been conducted on professional football players in Nigeria [10-16], studies among amateur players are generally sparse. It was therefore hypothesized that some associated factors may be responsible for football injuries among amateur football players in Kano. The purpose of this study was thus to evaluate football injuries and associated factors among male amateur football players in Kano State, North West Nigeria.

\section{Material and methods}

\section{Study design}

A descriptive, cross-sectional survey of male amateur football players in Kano, Kano State, North West Nigeria was performed.

\section{Recruitment and data collection}

A total of 7 amateur football clubs from Kano city were chosen purposely for the study after the 2016/ 2017 league season. Included were registered male football (soccer) players aged 16-30 years. Prior to the data collection, the aim of the study was explained to the participants after obtaining their consent and permission from the clubs' management. An adopted modified form of post-season injury questionnaire [17] was self-administered to obtain information about football injuries and associated factors during regular training sessions in August 2017. The modified form of post-season injury questionnaire consists of three sections: section A refers to demographic data and soccer background, section B concerns information on training, and section $\mathrm{C}$ is related to information on football injury. The questionnaire details are presented in the Appendix.

\section{Statistical analysis}

The descriptive statistics of mean, standard deviation, frequency, and percentage were used to summarize the data. Inferential chi-square statistics was applied to test the relationship between possible risk factors and football injuries across various body regions. All statistical analyses were performed with the IBM SPSS Statistics version 20.0 software (IBM Co., Armonk, USA) with the statistical significance level of $\alpha=0.05$.

\section{Ethical approval}

The research related to human use has complied with all the relevant national regulations and institutional policies, has followed the tenets of the Declaration of Helsinki, and has been approved by the research ethics committee of Kano State Sports Commission (KN/SC/18/EV0117).

\section{Informed consent}

Informed consent has been obtained from all individuals included in this study or their legal guardians.

\section{Results}

\section{General characteristic of the players}

A total number of 118 male football players (100\% response rate) with the mean age of 21.47 years (age range: 16-30) completed the study. The respondents were divided into 3 categories depending on age, with the age group of 16-20 years being the most numerous (46.6\%). The right foot was dominant in the majority of the players (71.2\%). The Junior Kano Pillars club had the highest number of players (25.4\%). Most footballers were midfielders in terms of the position played (39.0\%). All of them did stretching and the majority trained daily (88.1\%) and stretched before competition or training (78.0\%). Furthermore, a significant number of the players performed both skill and fitness training (75.4\%) as part of pre-training 
Table 1. General characteristic of the players

\begin{tabular}{|c|c|c|}
\hline Variables & $n$ & $\%$ \\
\hline \multicolumn{3}{|l|}{ Age categories } \\
\hline $16-20$ & 55 & 46.6 \\
\hline $21-25$ & 42 & 35.6 \\
\hline $26-30$ & 21 & 17.8 \\
\hline \multicolumn{3}{|l|}{ Gender } \\
\hline Male & 118 & 100 \\
\hline Female & 0 & 0 \\
\hline \multicolumn{3}{|l|}{ Club names } \\
\hline Junior Kano Pillars & 30 & 25.4 \\
\hline Shekarau Babes & 10 & 8.5 \\
\hline Zoo Road United & 20 & 16.9 \\
\hline Ramcy & 15 & 12.7 \\
\hline Samba Kurna & 15 & 12.7 \\
\hline FC Strikers & 15 & 12.7 \\
\hline Sky Limit & 13 & 11.0 \\
\hline \multicolumn{3}{|l|}{ Players' position } \\
\hline Keeper & 11 & 9.3 \\
\hline Defender & 34 & 28.8 \\
\hline Midfielder & 46 & 39.0 \\
\hline Striker & 27 & 22.9 \\
\hline \multicolumn{3}{|l|}{ Nature of training } \\
\hline Daily & 104 & 88.1 \\
\hline Alternate days & 14 & 11.9 \\
\hline Weekends & 0 & 0 \\
\hline \multicolumn{3}{|l|}{ Training activities } \\
\hline Skill training & 4 & 3.4 \\
\hline Fitness training & 25 & 21.2 \\
\hline Both & 89 & 75.4 \\
\hline \multicolumn{3}{|l|}{ Stretching } \\
\hline Yes & 118 & 100 \\
\hline No & 0 & 0 \\
\hline \multicolumn{3}{|l|}{ Time of stretching } \\
\hline Before training or match & 92 & 78.0 \\
\hline After training or match & 5 & 4.2 \\
\hline Both & 21 & 17.8 \\
\hline
\end{tabular}

activities. The general characteristics of the participants are presented in Table 1 . The mean number of years spent in the club was $2.42 \pm 1.12$ and the mean training duration was $1.71 \pm 6.55$ hours.

\section{Pattern of football injury}

As shown in Table 2, most injuries (78.3\%) occurred in the lower extremity, with knee injury being the most frequent (28.3\%), followed by ankle injury (21.7\%). Upper extremity injury accounted for $13.3 \%$, with shoulder and elbow being the most affected parts
Table 2. Patterns and causes of football injuries

\begin{tabular}{|c|c|c|}
\hline Variables & $n$ & $\%$ \\
\hline \multicolumn{3}{|l|}{ Body parts injured } \\
\hline Face & 1 & 1.7 \\
\hline Eyes & 0 & 0 \\
\hline Neck & 1 & 1.7 \\
\hline Upper back & 1 & 1.7 \\
\hline Lower back & 2 & 3.3 \\
\hline Shoulder & 5 & 8.3 \\
\hline Arm & 2 & 3.3 \\
\hline Elbow & 5 & 8.3 \\
\hline Wrist & 8 & 13.3 \\
\hline Knee & 17 & 28.3 \\
\hline Ankle & 13 & 21.7 \\
\hline Foot & 8 & 13.3 \\
\hline Thigh & 7 & 11.7 \\
\hline Leg & 2 & 3.3 \\
\hline \multicolumn{3}{|l|}{ Associated factors } \\
\hline Rough tackle from opponent & 41 & 67.2 \\
\hline Bad field of play & 6 & 9.8 \\
\hline Accidental twisting of leg & 1 & 1.6 \\
\hline Anxiety to win match & 1 & 1.6 \\
\hline Inappropriate footwear & 0 & 0 \\
\hline Inadequate training before match & 0 & 0 \\
\hline Fall & 5 & 8.2 \\
\hline Accidental collision with opponent & 7 & 11.6 \\
\hline
\end{tabular}

(8.3\% each). Rough tackle from an opponent was the major cause of football injury (67.2\%), followed by accidental collision with the opponent (11.7\%) and by bad field of play (9.8\%).

Association between age and football injuries across body regions

Table 3 shows the association between age and football injuries. Although the results show no significant relationship between age and football injuries for the particular body parts, the age category of 16-20 years sustained more football injuries than the other age groups.

Association between dominant leg and football injuries across body regions

Table 4 shows the association between the dominant leg and football injuries. No significant relationship between the dominant leg and football injuries for the particular body parts was observed, but the dominant leg sustained more injuries than the nondominant leg. 


\section{HUMAN MOVEMENT}

B. Bello, U.B. Sa'ad, A.A. Ibrahim, A.A. Mamuda, Pattern of sport injuries among amateur football players

Table 3. Association between age and football injuries across body regions

\begin{tabular}{|c|c|c|c|c|c|}
\hline \multirow{2}{*}{ Variables } & \multicolumn{3}{|c|}{ Age categories (years) } & \multirow{2}{*}{$\chi^{2}$} & \multirow{2}{*}{$p$} \\
\hline & $16-20$ & $21-25$ & $26-30$ & & \\
\hline \multicolumn{6}{|l|}{ Shoulder } \\
\hline Yes & 5 & 0 & 0 & \multirow{2}{*}{4.550} & \multirow{2}{*}{0.091} \\
\hline No & 50 & 42 & 21 & & \\
\hline \multicolumn{6}{|l|}{ Elbow } \\
\hline Yes & 3 & 0 & 2 & \multirow{2}{*}{3.631} & \multirow{2}{*}{0.122} \\
\hline No & 52 & 42 & 19 & & \\
\hline \multicolumn{6}{|l|}{ Wrist } \\
\hline Yes & 4 & 3 & 1 & \multirow{2}{*}{0.200} & \multirow{2}{*}{1.000} \\
\hline No & 51 & 39 & 20 & & \\
\hline
\end{tabular}

Thigh

\begin{tabular}{lrrrrr} 
Yes & 4 & 1 & 2 & 1.805 & 0.407 \\
No & 51 & 41 & 19 & & \\
\hline
\end{tabular}

Knee

\begin{tabular}{lrrrrr} 
Yes & 7 & 8 & 2 & 1.140 & 0.609 \\
No & 48 & 34 & 19 & & \\
\hline
\end{tabular}

Ankle

$\begin{array}{llll}\text { Yes } & 8 & 2 & 2\end{array}$

No

47

39

19

$1.281 \quad 0.541$

Foot

Yes

No

$\begin{array}{lll}5 & 2 & 1\end{array}$

$50 \quad 40 \quad 20$

$0.735 \quad 0.801$

Table 4. Association between dominant leg and football injuries across body regions

\begin{tabular}{|c|c|c|c|c|}
\hline \multirow{2}{*}{ Variables } & \multicolumn{2}{|r|}{ Leg } & \multirow{2}{*}{$\chi^{2}$} & \multirow{2}{*}{$p$} \\
\hline & Dominant & Non-dominant & & \\
\hline \multicolumn{5}{|l|}{ Thigh } \\
\hline Yes & 5 & 2 & \multirow{2}{*}{0.000} & \multirow{2}{*}{1.000} \\
\hline No & 79 & 32 & & \\
\hline \multicolumn{5}{|l|}{ Knee } \\
\hline Yes & 11 & 6 & \multirow{2}{*}{0.121} & \multirow{2}{*}{0.728} \\
\hline No & 73 & 38 & & \\
\hline \multicolumn{5}{|l|}{ Ankle } \\
\hline Yes & 10 & 3 & \multirow{2}{*}{0.025} & \multirow{2}{*}{0.873} \\
\hline No & 74 & 31 & & \\
\hline \multicolumn{5}{|l|}{ Foot } \\
\hline Yes & 4 & 4 & \multirow{2}{*}{0.933} & \multirow{2}{*}{0.344} \\
\hline No & 80 & 30 & & \\
\hline
\end{tabular}

Table 5. Association between playing position and football injuries across body regions

\begin{tabular}{|c|c|c|c|c|c|c|}
\hline \multirow{2}{*}{ Variable } & \multicolumn{4}{|c|}{ Player's position } & \multirow{2}{*}{$\chi^{2}$} & \multirow{2}{*}{$p$} \\
\hline & \multicolumn{4}{|c|}{ Keeper Defender Midfielder Striker } & & \\
\hline \multicolumn{7}{|l|}{ Shoulder } \\
\hline Yes & 2 & 0 & 2 & 1 & \multirow{2}{*}{5.291} & \multirow{2}{*}{0.087} \\
\hline No & 9 & 34 & 44 & 26 & & \\
\hline \multicolumn{7}{|l|}{ Elbow } \\
\hline Yes & 1 & 1 & 3 & 0 & \multirow{2}{*}{2.678} & \multirow{2}{*}{0.407} \\
\hline No & 10 & 33 & 43 & 27 & & \\
\hline \multicolumn{7}{|l|}{ Wrist } \\
\hline Yes & 2 & 3 & 2 & 1 & \multirow{2}{*}{3.245} & \multirow{2}{*}{0.353} \\
\hline No & 9 & 31 & 44 & 26 & & \\
\hline \multicolumn{7}{|l|}{ Thigh } \\
\hline Yes & 0 & 4 & 2 & 1 & \multirow{2}{*}{2.278} & \multirow{2}{*}{0.516} \\
\hline No & 11 & 30 & 44 & 26 & & \\
\hline \multicolumn{7}{|l|}{ Knee } \\
\hline Yes & 0 & 9 & 5 & 3 & \multirow{2}{*}{5.485} & \multirow{2}{*}{0.116} \\
\hline No & 11 & 25 & 41 & 34 & & \\
\hline \multicolumn{7}{|l|}{ Ankle } \\
\hline Yes & 1 & 2 & 3 & 2 & \multirow{2}{*}{2.801} & \multirow{2}{*}{0.386} \\
\hline No & 10 & 32 & 38 & 25 & & \\
\hline \multicolumn{7}{|l|}{ Foot } \\
\hline Yes & 0 & 2 & 3 & 3 & \multirow{2}{*}{1.252} & \multirow{2}{*}{0.757} \\
\hline No & 11 & 32 & 43 & 34 & & \\
\hline
\end{tabular}

Association between playing position and football injuries across body regions

Table 5 shows the association between the playing position and football injuries. The results revealed no relationship between football injuries in various body regions and the players' position. However, midfielders tended to have more injuries, followed by defenders, strikers, and goalkeepers.

Association between previous injury and football injuries across body regions

Table 6 highlights the association between previous injury and football injuries across various body regions. It was revealed that most of the injuries (those of the shoulder, elbow, wrist, ankle, and foot) had no relationship with previous injury. However, a significant association was observed between previous injury and the injuries of thigh and knee. 
Table 6. Association between previous injury and football injuries across body regions

\begin{tabular}{lrrrr}
\hline \multirow{2}{*}{ Variables } & \multicolumn{2}{c}{ Previous injury } & \multirow{2}{*}{$\chi^{2}$} & $p$ \\
\cline { 2 - 3 } & \multicolumn{1}{c}{ Yes } & No & & \\
\hline Shoulder & & & & \\
$\quad$ Yes & 3 & 2 & 0.073 & 0.787 \\
No & 24 & 32 & & \\
\hline Elbow & & & & \\
Yes & 1 & 4 & & \\
No & 26 & 30 & & \\
\hline Wrist & & & & \\
Yes & 3 & 5 & 0.449 & 0.001 \\
$\quad$ No & 34 & 29 & & 0.975 \\
\hline
\end{tabular}

\begin{tabular}{lrrrr}
\hline $\begin{array}{l}\text { Thigh } \\
\text { Yes }\end{array}$ & 0 & 7 & & \\
No & 27 & 27 & 4.416 & $0.036^{*}$ \\
\hline Knee & & & & \\
Yes & 12 & 5 & 5.224 & $0.022^{*}$ \\
No & 15 & 29 & & \\
\hline Ankle & & & & \\
Yes & 9 & 4 & 2.988 & 0.084 \\
No & 18 & 30 & & \\
\hline Foot & & & & \\
Yes & 4 & 4 & 0.000 & 1.000 \\
No & 23 & 30 & & \\
\hline
\end{tabular}

* significant at $p<0.05$

Table 7. Types of treatment received by players

\begin{tabular}{lrc}
\hline Variable & $n$ & $\%$ \\
\hline Self-treatment & 26 & 42.6 \\
First aid & 19 & 31.1 \\
Physiotherapy only & 7 & 11.5 \\
Combination of all & 9 & 14.8 \\
\hline
\end{tabular}

\section{Treatment type}

Table 7 presents different types of treatment received by the players after sustaining a football injury. The majority of the players (42.6\%) applied self-treatment. This was followed by first aid (31.1\%) and sole physical therapy $(11.5 \%)$.

\section{Discussion}

The aim of the study was to evaluate football injuries and associated factors among male amateur football players in Kano State, Nigeria.
The research revealed that lower limbs were more affected compared with upper limbs, which is in tandem with most findings in the literature [4-6, 18]. Focusing on the lower limb, we found that the knee (28.3\%) was most commonly injured, followed by ankle (21.7\%). In contrast, Ekstrand et al. [9] observed that the thigh was most frequently affected, followed by ankle and knee among men footballers. In another study, Ibikunle et al. [10] reported that ankle injuries were most common, followed by knee injuries among female players. The most common risk factor for football injuries among amateur football players in Kano is rough tackle from an opponent (67.2\%), followed by accidental collision with the opponent $(11.7 \%)$, bad field of play (9.8\%), and fall (8.2\%). Other risk factors include accidental twisting of the leg or anxiety to win a match. This result is similar to the findings of previous studies among professional football players $[9,14,18]$ that revealed that about $62-86 \%$ of the injuries in football were caused by tackling by an opponent, and the rest by own foul. It has also been found in the literature that about $16-28 \%$ of football injuries are caused by foul play [10].

Although the majority of the players in our study spent a few years (mean: 2.4 years) with their clubs, it is interesting to note that most of them performed training for nearly 2 hours, and the mean training lasted approximately 1.7 hours. This is very important as adequate training is essential to reducing the risk of football injuries. However, the specific warm-up stretching protocol that the trainers or the players themselves applied for training is not clear. The FIFA $11+$ injury prevention program was designed to address all soccer-related injuries [5] and has been documented to be effective in decreasing the overall injury rate in both male and female soccer players [6-8, 11]. It is likely that the players in this study applied some stretching techniques similar to those included in the FIFA $11+$ as the general injury rate in different parts of the body was low, although this specific information was not inquired during the data collection.

We found no significant association between age and football injuries, even though age is one of the risk factors for sports injuries. Still, the results show that younger players, aged 16-20 years, underwent more injuries as they tend to be more aggressive during the play. Previous studies [9, 18, 19] revealed that junior players aged 17-18 years had similar or slightly higher injury incidence than the high level adult players.

For the dominant leg, we found no significant association between football injuries and the dominant leg. However, the results relatively show that the dominant 
B. Bello, U.B. Sa’ad, A.A. Ibrahim, A.A. Mamuda, Pattern of sport injuries among amateur football players

leg sustained more of the presented injuries. Similarly, Ekstrand et al. [9] observed that the dominant leg underwent most of the injuries among players. This may be due to the overuse of the leg in sporting activities such as kicking, cutting, dribbling, and foul from the opponent, making it more exposed to injuries.

No significant association could be found between the players' position and football injuries, which is in harmony with the results among professional players $[9,20]$ but contrary to the observations by Azubuike and Okojie [12], who noted significant association between the player's role and the mechanism of injury. Nevertheless, our results suggest a trend that midfielders and defenders sustained more injuries than keepers or strikers.

The association between previous injury and football injuries across various body parts was only significant for thigh and knee injuries. Ekstrand et al. [9] found previous injury to be a risk factor for knee and ankle injury. According to Chomiak et al. [21], inadequate rehabilitation from previous injury constitutes a risk factor for another thigh (strain, tendinosis) injury. In present the study, it is likely that these injuries did not receive adequate rehabilitation as the majority of the clubs lack medical rehabilitation teams. Furthermore, the most numerous group of players in this study were found to have self-treatment, followed by first aid and then physiotherapy. This suggests a low level of awareness of physiotherapy and athletic trainers' role in the management of football injuries. Previous studies have also shown that much training and participation can as well lead to high prevalence of sporting injuries [22-23]. Thus, not only the medical team but also the coaches and trainers should be responsible for injury prevention and rehabilitation.

The present study has some limitations, which should be taken into account when interpreting the findings. Firstly, the research only recruited male amateur football players using a non-probability sampling technique; hence the results may not be generalized. Secondly, a self-report questionnaire was applied to obtain information on football injuries and associated factors, which might be subject to recall bias. Finally, we only focused on certain intrinsic factors associated with the occurrence of football injury. Other intrinsic factors such as injury type and state of mind were not involved. Additionally, we did not analyse extrinsic factors such as weather conditions or the nature of football field, which were recognized in similar studies [10, 12]. Further studies with similar objectives should consider the probability sampling tech- nique, female amateur footballers, and other potential associated factors that are likely to influence the occurrence of football injuries not only in the North West Nigeria but also in other regions so as to correlate the findings within the country.

The present study was not carried out to assess the preventive strategy for football injuries among adolescent players. It is, though, pertinent to note that there is a need to educate players, coaches, as well as club managers on injury prevention programs such as comprehensive warm-up as proposed by FIFA 11+, the use of protective equipment, etc. The programs should be enforced for all registered amateur clubs not only within a state, but also at the national level. This would help reduce the rate of injury among adolescent players, leading to better performance and lower withdrawal or out-of-play time due to injury.

\section{Conclusions}

The most common risk factor for football injuries among male amateur football players in Kano State in Nigeria is rough tackling from an opponent.

\section{Acknowledgments}

The authors would like to thank all the consented subjects for their cooperation and willingness to be part of this study.

\section{Disclosure statement}

No author has any financial interest or received any financial benefit from this research.

\section{Conflict of interest}

The authors state no conflict of interest.

\section{References}

1. FIFA. FIFA Big Count 2006: 270 million people active in football. FIFA Communications Division, Information Services; 2007. Available from: https://www.fifa. $\mathrm{com} / \mathrm{mm} /$ document/fifafacts/bcoffsurv/bigcount. statspackage_7024.pdf.

2. Hägglund M, Waldén M, Magnusson H, Kristenson K, Bengtsson H, Ekstrand J. Injuries affect team performance negatively in professional football: an 11year follow-up of the UEFA Champions League injury study. Br J Sports Med. 2013;47(12):738-742; doi: 10.1136/bjsports-2013-092215.

3. Maro CN, Roberts GC, Sørensen M. Using sport to promote HIV/AIDS education for at-risk youths: an intervention using peer coaches in football. Scand J Med Sci Sports. 2009;19(1):129-141; doi: 10.1111/j.1600-0838. 2007.00744.x. 
4. Longo UG, Loppini M, Cavagnino R, Maffulli N, Denaro V. Musculoskeletal problems in soccer players: current concepts. Clin Cases Miner Bone Metab. 2012; |9(2):107-111.

5. Bizzini M, Dvorak J. FIFA 11+: an effective programme to prevent football injuries in various player groups worldwide - a narrative review. Br J Sports Med. 2015; 49(9):577-579; doi: 10.1136/bjsports-2015-094765.

6. Silvers-Granelli H, Mandelbaum B, Adeniji O, Insler S, Bizzini M, Pohlig R, et al. Efficacy of the FIFA 11+ injury prevention program in the collegiate male soccer player. Am J Sports Med. 2015;43(11):2628-2637; doi: 10.1177/0363546515602009.

7. Grooms DR, Palmer T, Onate JA, Myer GD, Grindstaff T. Soccer-specific warm-up and lower extremity injury rates in collegiate male soccer players. J Athl Train. 2013;48(6):782-789; doi: 10.4085/1062-605048.4.08.

8. Soligard T, Myklebust G, Steffen K, Holme I, Silvers H, Bizzini M, et al. Comprehensive warm-up programme to prevent injuries in young female footballers: cluster randomised controlled trial. BMJ. 2008;337:a2469; doi: 10.1136/bmj.a2469.

9. Ekstrand J, Hägglund M, Waldén M. Epidemiology of muscle injuries in professional football (soccer). Am J Sports Med. 2011;39(6):1226-1232; doi: 10.1177/ 0363546510395879.

10. Ibikunle PO, Efobi KC, Nwankwo MJ, Ani KU. UEFA model in identification of types, severity and mechanism of injuries among footballers in the Nigerian Women's Premier League. BMJ Open Sport Exerc Med. 2019; 5(1):e000386; doi: 10.1136/bmjsem-2018-000386.

11. Owoeye OBA, Aiyegbusi AI, Fapojuwo OA, Badru OA, Babalola AR. Injuries in male and female semi-professional football (soccer) players in Nigeria: prospective study of a National Tournament. BMC Res Notes. 2017;10:133; doi: 10.1186/s13104-017-2451-x.

12. Azubuike SO, Okojie OH. An epidemiological study of football (soccer) injuries in Benin City, Nigeria. Br J Sports Med. 2009;43(5):382-386; doi: 10.1136/bjsm. 2008.051565.

13. Dvorak J, Junge A, Derman W, Schwellnus M. Injuries and illnesses of football players during the 2010 FIFA World Cup. Br J Sports Med. 2011;45(8):626-630; doi: 10.1136/bjsm.2010.079905.

14. Owoeye OBA, Nwachukwu A, Akinbo SRA. Injuries in Nigerian national female footballers at the 2008 Beijing Olympic Games, China: a prospective case study. Afr J Physiother Rehabil Sci. 2012;4(1-2):57-61; doi: 10.4314/ajprs.v4i1-2.9.

15. Akinbo SRA, Salau MA, Odebiyi DO, Ibeabuchi NM. Video analysis of musculoskeletal injuries in Nigerian and English professional soccer leagues: a comparative study. Niger J Health Biomed Sci. 2007;6(2):8589; doi: 10.4314/njhbs.v6i2.11650.

16. Ataikpo AO. Injury pattern of the National Female Soccer Team of Nigeria from 1997-1999. J Niger Med Rehabil Ther. 2001;6(1):11-15.
17. Abdenour TE. Postseason Injury Questionnaire. Phys Sportsmed. 1983;11(10):179; doi: 10.1080/00913847. 1983.11708670.

18. Sadigursky D, Braid JA, De Lira DNL, Machado BAB, Carneiro RJF, Colavolpe PO. The FIFA 11+ injury prevention program for soccer players: a systematic review. BMC Sports Sci Med Rehabil. 2017;9:18; doi: 10.1186/ s13102-017-0083-z.

19. Hawkins RD, Fuller CW. An examination of the frequency and severity of injuries and incidents at three levels of professional football. Br J Sports Med. 1998; 32(4):326-332; doi: 10.1136/bjsm.32.4.326.

20. Morgan BE, Oberlander MA. An examination of injuries in major league soccer: the inaugural season. Am J Sports Med. 2001;29(4):426-430; doi: 10.1177/03635 465010290040701.

21. Chomiak J, Junge A, Peterson L, Dvorak J. Severe injuries in football players. Influencing factors. Am J Sports Med. 2000;28(5 Suppl.):S58-S68; doi: 10.1177/28. suppl_5.s-58.

22. Costa FE, Dal Pupo J, Barth J, Bezerra ES, Salvador AF. The prevalence of injuries and its association with the characteristics of training in American football players in Brazil. Hum Mov. 2019;20(1):31-37; doi: 10.5114/hm.2019.79041.

23. Malliaropoulos N, Mertyri D, Tsaklis P. Prevalence of injury in ultra trail running. Hum Mov. 2015;16(2):5259; doi: 10.1515/humo-2015-0026.

\section{Appendix}

Modified post-season injury questionnaire

\section{SECTION A \\ DEMOGRAPHIC DATA}

1. Age

2. Sex

SOCCER BACKGROUND

1. Name of club

2. National league division

a. Globacom premier league [ ]

b. Nigeria National league [ ]

c. Amateur league [ ]

3. What is your position in the club?
a. Keeping
b. Defence
c. Midfielder
d. Striker

4. Which is your dominant leg?
a. Right [ ]
b. Left [ ]

5. How long have you been playing for your club?
a. 1 year [ ]
b. 2 years [ ]
c. 3 years [ ]
d. more (specify) 


\section{HUMAN MOVEMENT}

B. Bello, U.B. Sa'ad, A.A. Ibrahim, A.A. Mamuda, Pattern of sport injuries among amateur football players

\section{SECTION B}

TRAINING

1. How often do you train before match
a. Daily [ ]
b. Alternate days [ ]
c. At weekends [ ]
d. A few days before the match [ ]

2. How many hours do you train before the match?
a. 1 [ ]
b. 2 [ ]
c. 3 [ ]
d. 4 [ ]
e. Above 4 (specify)

3. Do you do any of the following before the training?
a. Skills training [ ]
b. Fitness training [ ]
c. Both [ ]

4. Do you any stretching?
a. Yes [ ]
b. No [ ]

5. If yes, when do you do stretching?
a. Before the training or match [ ]
b. After the training or match [ ]
c. Both [ ]

\section{SECTION C}

\section{FOOTBALL INJURY}

1. Have you sustained any injury while playing for your club for the last 1 year?
a. Yes [ ]
b. No [ ]

2. On which of the following body parts and structures did you sustain injury? (One or more answer(s) are possible). State number of times for the complete season.

\section{HEAD:}

Skull [ ]

Face [ ]

Eyes [ ]

Other (specify)

SPINE/TRUNK:

Neck [ ]

Upper back [ ]

Lower back [ ]

Ribs/chest [ ]

UPPER EXTREMITY:

Shoulder [ ]

Arm [ ]

Elbow [ ]

Forearm [ ]

Wrist [ ]

Hand [ ]

Finger [ ]

\section{LOWER EXTREMITY:}

Pelvis [ ]

Hip [ ]

Thigh [ ]

Knee [ ]

Leg [ ]

Ankle [ ]

Achilles [ ]

Foot [ ]

1. At what time did you sustained the injury?

a. During the training [ ]

b. During the competition [ ]

2. Have you ever had an injury before on the same part?
a. Yes [ ]
b. No [ ]

3. Did the injury put you out of play?
a. Yes [ ]
b. No [ ]

4. If yes, for how long were you out of play?
a. 1 week [ ]
b. 2 weeks [ ]
c. 3 weeks [ ]
d. More (specify)

5. Are you still feeling any symptoms on the injured part?
a. Yes [ ]
b. No [ ]

6. What do you think is the cause of the injury?
a. Rough tackle from an opponent [ ]
b. Bad field of play [ ]
c. Inadequate training before match [ ]
d. Anxiety to win a match [ ]
e. Accidental twisting of the leg [ ]
f. Bad weather of play (rain, cold, etc.) [ ]
g. Insufficient playing kit (boots, jersey, shin-guard, etc.) [ ]
h. Accidental collision with the opponent [ ]
i. Frustrating due to poor officiating [ ]
j. Other (specify).

7. Was the injury treated?
a. Yes [ ]
b. No [ ]

8. If yes, what type of treatment?
a. Self-treatment [ ]
b. First aids [ ]
c. Physiotherapy only [ ]
d. Combination of a, b, and c [ ]
e. Other (specify) 